\title{
Importance of finding the bona fide target of the Fanconi anemia pathway
}

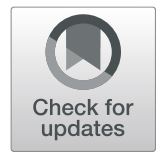

Wataru Sakai ${ }^{*}$ and Kaoru Sugasawa

\begin{abstract}
Fanconi anemia (FA) is a rare genetic disease characterized by the deficiency of the cellular response and repair pathway for DNA interstrand crosslink (ICL) damage. Although recent studies have revealed the detailed molecular functions of FA proteins encoded by 22 genes, the mechanism of occurrence of endogenous ICLs in the human body remains poorly understood. In this short review, we summarize the potential endogenous sources of ICLs counteracted by FA proteins, and provide perspectives on the unanswered questions regarding FA.
\end{abstract}

Keywords: Fanconi anemia, Aldehyde, DNA damage, DNA repair

\section{Introduction}

Fanconi anemia (FA) is a genetically and phenotypically heterogeneous recessive disease associated with congenital abnormalities, bone marrow failure (BMF), and a predisposition to both hematologic malignancies and solid tumors. Moreover, endocrine abnormalities, such as dyslipidemia and metabolic syndrome are common in patients with FA [1]. At present, 22 genes responsible for FA have been identified, and all the encoded proteins function in an intracellular signaling pathway, designated as the FA pathway, which regulates the response to and repair of DNA interstrand crosslinks (ICLs) (Table 1, and Fig. 1). Therefore, at the cellular level, FA is characterized by hypersensitivity to ICLs induced by chemical agents, such as mitomycin C and cisplatin [2]. Bone marrow transplantation is the only known cure for FA-associated hematologic malignancies; however, safe and effective therapies for treating or preventing the increased risk of solid tumors have not yet been established. The two longstanding questions in FA research are, "What are the natural causes of ICLs?" and "What is the origin of these causes?" Even in the absence of environmental exposure to ICL-inducing agents, patients with FA display clinical symptoms at birth or in early life. Detailed mechanisms of these symptoms remain unclear; however, recent studies have revealed important insights into the pathogenesis of FA (see below).

\footnotetext{
* Correspondence: wsakai@phoenix.kobe-u.ac.jp

Biosignal Research Center, and Graduate School of Science, Kobe University, 1-1 Rokkodai, Nada, Kobe, Hyogo 657-8501, Japan
}

\section{Acetaldehyde and formaldehyde}

A wide variety of reactive aldehydes are ubiquitously found in the environment. Acetaldehydes are the major by-products of the catabolic metabolism of alcoholic beverages [3]. Formaldehyde is not only a chemical compound present in some cosmetics and foods, but also a naturally-occurring compound in the human body $[4,5]$. The International Agency for Research on Cancer categorizes these aldehydes into "Group 1," the highest risk factors for carcinogenicity. Recently, an understanding of the effect of these small aldehydes has yielded significant progress on our view of the pathogenesis of FA. Aldehyde dehydrogenase 2 (ALDH2) and alcohol dehydrogenase 5 (ADH5) play important roles in acetaldehyde and formaldehyde detoxification, respectively. Both enzymes oxidize aldehydes, thereby reducing its genotoxic effects. Interestingly, human and chicken FA-deficient cells have been shown to be hypersensitive to plasma levels of formaldehyde without any defect on both ALDH2 and ADH5 [6]. Mice deficient in Aldh2 displayed chromosomal aberrations and increased mutagenesis in their hematopoietic stem cells [7]. Moreover, combined inactivation of FA genes and Aldh2 or Adh5 demonstrated developmental defects, BMF, and a predisposition to leukemia [8-11]. About 540 million of the world's population, particularly the East Asians, carry a dominant-negative allele (rs671) of $A L D H 2$ [12]. Alcohol consumption by the individuals with this variant is strongly associated with higher risks of esophageal and rectal cancer [13, 14]. Remarkably, the homozygosity of the $A L D H 2$ variant in Japanese patients

(c) The Author(s). 2019 Open Access This article is distributed under the terms of the Creative Commons Attribution 4.0 International License (http://creativecommons.org/licenses/by/4.0/), which permits unrestricted use, distribution, and 
Table 1 The FA gene products and their functions

\begin{tabular}{ll}
\hline FA protein (alias) & Function \\
\hline FANCA & FA core complex \\
FANCB & FA core complex \\
FANCC & FA core complex \\
FANCD1 (BRCA2) & Homologous recombination \\
FANCD2 & ID complex \\
FANCE & FA core complex \\
FANCF & FA core complex \\
FANCG & FA core complex \\
FANCI & ID complex \\
FANCJ (BRIP1) & Homologous recombination \\
FANCL & FA core complex, ubiquitin ligase \\
FANCM & FA core complex, helicase \\
FANCN (PALB2) & Homologous recombination \\
FANCO (RAD51C) & Homologous recombination \\
FANCP (SLX4) & ICL unhooking \\
FANCQ (ERCC4/XPF) & ICL unhooking, structure-specific endonuclease \\
FANCR (RAD51) & Homologous recombination \\
FANCS (BRCA1) & Homologous recombination \\
FANCT (UBE2T) & Ubiquitin-conjugating enzyme \\
FANCU (XRCC2) & Homologous recombination \\
FANCV (MAD2L2/REV7) & Translesion synthesis \\
FANCW (RFWD3) & Homologous recombination, ubiquitin ligase \\
\hline &
\end{tabular}

with FA is associated with accelerated progression of BMF compared to the heterozygotes [15]. All these results strongly suggest that the level of endogenous aldehydes is important for the pathogenesis of FA.

\section{Lipid peroxidation-derived aldehydes}

Lipids are crucial cellular membrane components, as well as essential energy sources in the human body; however, lipid metabolism and peroxidation produce a variety of aldehydes, such as 4-hydroxynonenal (4HNE) and malondialdehyde (MDA) [16]. These aldehydes are abundant in the human body, and react with proteins and DNA to form biomolecule adducts associated with carcinogenesis and neurodegenerative diseases [16, 17]. MDA is one of the most predominant products of lipid peroxidation, and is generated primarily by decomposition of poly-unsaturated fatty acids with at least two methylene-interrupted double bonds [17]. Although it has been proposed that MDA could form ICLs and is mutagenic in human cells [18], the chemical reactivity of MDA is not high under physiological conditions [19]. Conversely, MDA has a unique ability to form hybrid products with acetaldehyde and formaldehyde. Notably, these "hybrid aldehydes" can react with nucleosides and amino acids under physiological conditions, indicating

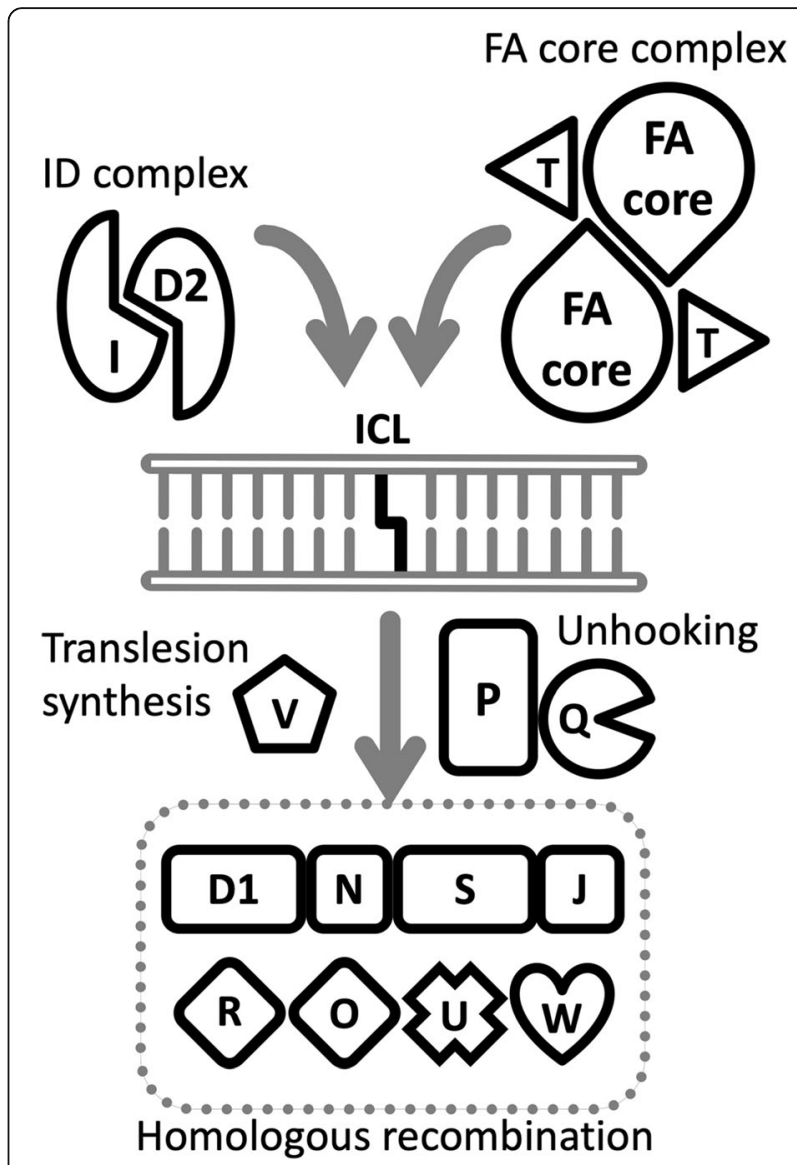

Fig. 1 A model for the canonical FA pathway. The FA core complex is a multiple protein complex which contains a homo-dimeric module for ubiquitination. FANCT acts as a ubiquitin-conjugating enzyme associated with the FA core complex. FANCD2 and FANCI form a heterodimer (ID complex), and are known as targets for monoubiquitination mediated by the FA core complex. FANCP and FANCQ are involved in DNA strand incisions on either side of the ICL (a process called "unhooking"). FANCV is an accessory subunit of DNA polymerase $\zeta$ involved in translesion synthesis over the unhooked ICL. At the final step of $\mathrm{ICL}$ repair, a homologous recombination-mediated process restores the fidelity of the genome. For more detailed mechanisms of the canonical FA pathway, see a review in [34]

their ability to form ICLs or protein adducts [20-22]. Some studies have reported intriguing implications of lipid metabolism in FA. Endocrine abnormalities including dyslipidemia, obesity, and metabolic syndrome are present in more than $70 \%$ of FA patients [23]. At the cellular level, metabolome analysis of mesenchymal stromal cells from FA-knockout mice revealed abnormal lipid profiles, especially in glycerophospholipid biosynthesis [24]. FA-deficient human cells also show accumulation of lipid droplets (LDs) [25], which are nuclear and cytoplasmic organelles that store neutral lipids and are important for energy metabolism. Recently, it has been suggested that LDs may serve as a biomarker for metabolic diseases [26]. Consistent with these results, lipidomic profiling in 
FA-deficient human keratinocytes also showed upregulation of glycosphingolipids [27]. Further analyses are required to elucidate whether these lipid-related dysregulations in FA depend on the secondary effects of the deficiency in the canonical FA pathway or they are the direct effects of the unknown function(s) of FA proteins.

\section{Conclusions}

An understanding of natural ICLs may play an important role in the development of an effective treatment for FA. Avoiding exposure to endogenous ICL sources or reducing the occurrence of endogenous ICLs may suppress the onset of FA pathogenesis. Indeed, avoidance of sun-exposure is an effective treatment for patients with xeroderma pigmentosum, which is associated with a deficiency of nucleotide excision repair that removes DNA lesions induced by sunlight (ultraviolet radiation) [28]. Alternatively, an understanding of natural ICLs has allowed the development of molecular-targeted drugs, such as alda-1 (ALDH2 agonist) and metformin (aldehyde scavenger) [29, 30], for the prevention of cancer or BMF in patients with FA.

Over the last two decades, researchers have made great progress in elucidating the molecular mechanisms involving FA proteins. The functional integrity of FA proteins is also important for acquired resistance to anticancer drugs [31-33]. However, there are still some questions to be answered in FA research. Finding the bona fide target of the FA pathway would not only contribute to the alleviation of FA symptoms, but also improve the quality of life of humans in general.

\section{Abbreviations}

ADH: Alcohol dehydrogenase; ALDH: Aldehyde dehydrogenase; BMF: Bone marrow failure; FA: Fanconi anemia; ICL: Interstrand crosslink; MDA: Malondialdehyde

\section{Acknowledgments}

We thank Dr. Manabu Yasui, Dr. Shigeharu Muto, Dr. Akira Sassa, Organizer of 2018 JEMS Symposium, and the Japanese Environmental Mutagen Society. We thank the members of Biosignal Research Center, and Department of Biology, Graduate School of Science, Kobe University, for helpful discussions and encouragement.

\section{Funding}

WS is financially supported by a Grant-in-Aid from the Japan Society for the Promotion of Science (JSPS KAKENHI Grant Number 17 K07286).

\section{Availability of data and materials}

Not applicable.

\section{Authors' contributions}

WS and KS contributed to drafting the manuscript. Both authors approved the final manuscript.

\section{Ethics approval and consent to participate}

Not applicable.

\section{Consent for publication}

Not applicable.

\section{Competing interests}

The authors declare that they have no competing interests.

\section{Publisher's Note}

Springer Nature remains neutral with regard to jurisdictional claims in published maps and institutional affiliations.

Received: 27 December 2018 Accepted: 14 February 2019

Published online: 06 March 2019

\section{References}

1. Auerbach AD. Fanconi anemia and its diagnosis. Mutat Res. 2009;668:4-10.

2. Ceccaldi R, Sarangi P, D'Andrea AD. The Fanconi anaemia pathway: new players and new functions. Nat Rev Mol Cell Biol Nature Publishing Group. 2016;17:337-49.

3. Roswall N, Weiderpass E. Alcohol as a risk factor for cancer: existing evidence in a global perspective. J Prev Med Public Health. 2015;48:1-9.

4. Heck HD, Casanova M. The implausibility of leukemia induction by formaldehyde: a critical review of the biological evidence on distant-site toxicity. Regul Toxicol Pharmacol. 2004;40:92-106.

5. Burgos-Barragan G, Wit N, Meiser J, Dingler FA, Pietzke M, Mulderrig L, et al. Mammals divert endogenous genotoxic formaldehyde into one-carbon metabolism. Nature. 2017;548:549-54

6. Ridpath JR, Nakamura A, Tano K, Luke AM, Sonoda E, Arakawa H, et al. Cells deficient in the FANC/BRCA pathway are hypersensitive to plasma levels of formaldehyde. Cancer Res American Association for Cancer Research. 2007; 67:11117-22.

7. Garaycoechea Jl, Crossan GP, Langevin F, Mulderrig L, Louzada S, Yang F, et al. Alcohol and endogenous aldehydes damage chromosomes and mutate stem cells. Nature Nature Publishing Group. 2018;553:171-7.

8. Langevin F, Crossan GP, Rosado IV, Arends MJ, Patel KJ. Fancd2 counteracts the toxic effects of naturally produced aldehydes in mice. Nature. 2011:475: $53-8$

9. Oberbeck N, Langevin F, King G, de Wind N, Crossan GP, Patel KJ. Maternal aldehyde elimination during pregnancy preserves the fetal genome. Mol Cell. 2014;55:807-17.

10. Garaycoechea JI, Crossan GP, Langevin F, Daly M, Arends MJ, Patel KJ. Genotoxic consequences of endogenous aldehydes on mouse haematopoietic stem cell function. Nature. 2012;489:571-5.

11. Pontel LB, Rosado IV, Burgos-Barragan G, Garaycoechea JI, Yu R, Arends MJ, et al. Endogenous formaldehyde is a hematopoietic stem cell Genotoxin and metabolic carcinogen. Mol Cell. 2015;60:177-88.

12. Brooks PJ, Enoch M-A, Goldman D, Li T-K, Yokoyama A. The alcohol flushing response: an unrecognized risk factor for esophageal cancer from alcohol consumption. PLoS Med. Public Libr Sci. 2009;6:e50.

13. Matsuo K, Hamajima N, Shinoda M, Hatooka S, Inoue M, Takezaki T, et al. Gene-environment interaction between an aldehyde dehydrogenase-2 (ALDH2) polymorphism and alcohol consumption for the risk of esophageal cancer. Carcinogenesis. 2001;22:913-6.

14. Matsuo K, Hamajima N, Hirai T, Kato T, Koike K, Inoue M, et al. Aldehyde dehydrogenase 2 (ALDH2) genotype affects rectal cancer susceptibility due to alcohol consumption. J Epidemiol. 2002;12:70-6.

15. Hira A, Yabe H, Yoshida K, Okuno Y, Shiraishi Y, Chiba K, et al. Variant ALDH2 is associated with accelerated progression of bone marrow failure in Japanese Fanconi anemia patients. Blood. 2013;122:3206-9.

16. Nair U, Bartsch H, Nair J. Lipid peroxidation-induced DNA damage in cancer-prone inflammatory diseases: a review of published adduct types and levels in humans. Free Radic Biol Med. 2007;43:1109-20.

17. Voulgaridou G-P, Anestopoulos I, Franco R, Panayiotidis MI, Pappa A. DNA damage induced by endogenous aldehydes: current state of knowledge. Mutat Res. 2011;711:13-27.

18. Niedernhofer LJ, Daniels JS, Rouzer CA, Greene RE, Marnett LJ. Malondialdehyde, a product of lipid peroxidation, is mutagenic in human cells. J Biol Chem. 2003;278:31426-33.

19. Pizzimenti S, Ciamporcero E, Daga M, Pettazzoni P, Arcaro A, Cetrangolo G, et al. Interaction of aldehydes derived from lipid peroxidation and membrane proteins. Front Physiol. Frontiers; 2013;4:242.

20. Pluskota-Karwatka D, Le Curieux F, Munter T, Sjöholm R, Kronberg L Formation of conjugate adducts in the reactions of malonaldehydeacetaldehyde and malonaldehyde-formaldehyde with guanosine. Chem Res Toxicol. 2005;18:300-7. 
21. Pluskota-Karwatka D, Le Curieux F, Munter T, Sjöholm R, Kronberg L. Identification of conjugate adducts formed in the reactions of malonaldehyde-acetaldehyde and malonaldehyde-formaldehyde with cytidine. Chem Res Toxicol. 2002;15:110-7.

22. Nakamura J, Shimomoto T, Collins LB, Holley DW, Zhang Z, Barbee JM, et al. Evidence that endogenous formaldehyde produces immunogenic and atherogenic adduct epitopes. Sci Rep. Nat Publ Group. 2017;7:10787.

23. Giri N, Batista DL, Alter BP, Stratakis CA. Endocrine abnormalities in patients with Fanconi anemia. J Clin Endocrinol Metab. 2007;92:2624-31.

24. Amarachintha S, Sertorio M, Wilson A, Li X, Pang Q. Fanconi Anemia mesenchymal stromal cells-derived Glycerophospholipids skew hematopoietic stem cell differentiation through toll-like receptor signaling. Stem Cells. 2015;33:3382-96.

25. Ravera S, Degan P, Sabatini F, Columbaro M, Dufour C, Cappelli E. Altered lipid metabolism could drive the bone marrow failure in fanconi anaemia. Br. J. Haematol. Wiley/Blackwell (10.1111). 2018;1863:1214.

26. Geng F, Guo D. Lipid droplets, potential biomarker and metabolic target in glioblastoma. Intern Med Rev (Wash D C). 2017;3(5). https://doi.org/10. 18103/imr.v3i5.443.

27. Zhao X, Brusadelli MG, Sauter SL, Butsch Kovacic M, Zhang W, RomickRosendale $L E$, et al. Lipidomic profiling links the Fanconi anemia pathway to glycosphingolipid metabolism in head and neck cancer cells. Clin Cancer Res. 2018;24(11):2700-9.

28. Lambert WC, Lambert MW. Development of effective skin cancer treatment and prevention in xeroderma pigmentosum. Photochem Photobiol. 2nd ed. Wiley/Blackwell (10.1111). 2015;91:475-83.

29. Chen C-H, Budas GR, Churchill EN, Disatnik M-H, Hurley TD, Mochly-Rosen D. Activation of aldehyde dehydrogenase-2 reduces ischemic damage to the heart. Science American Association for the Advancement of Science. 2008;321:1493-5.

30. Zhang Q-S, Tang W, Deater M, Phan N, Marcogliese AN, Li H, et al. Metformin improves defective hematopoiesis and delays tumor formation in Fanconi anemia mice. Blood American Society of Hematology. 2016;128: 2774-84.

31. Sakai W, Swisher EM, Karlan BY, Agarwal MK, Higgins J, Friedman C, et al. Secondary mutations as a mechanism of cisplatin resistance in BRCA2mutated cancers. Nature. 2008:451:1116-20.

32. Sakai W, Swisher EM, Jacquemont C, Chandramohan KV, Couch FJ, Langdon $\mathrm{SP}$, et al. Functional restoration of BRCA2 protein by secondary BRCA2 mutations in BRCA2-mutated ovarian carcinoma. Cancer Res. 2009;69:6381-6.

33. Swisher EM, Sakai W, Karlan BY, Wurz K, Urban N, Taniguchi T. Secondary BRCA1 mutations in BRCA1-mutated ovarian carcinomas with platinum resistance. Cancer Res. 2008:68:2581-6.

34. Hashimoto S, Anai H, Hanada K. Mechanisms of interstrand DNA crosslink repair and human disorders. Genes Environ. BioMed Central. 2016;38:9.

Ready to submit your research? Choose BMC and benefit from:

- fast, convenient online submission

- thorough peer review by experienced researchers in your field

- rapid publication on acceptance

- support for research data, including large and complex data types

- gold Open Access which fosters wider collaboration and increased citations

- maximum visibility for your research: over $100 \mathrm{M}$ website views per year

At BMC, research is always in progress.

Learn more biomedcentral.com/submissions 